\section{LETTERS TO THE EDITOR}

\section{Relation between electromyography and anal manometry of the external anal sphincter}

SIR,-Sørensen et al (Gut, 1991, 32, 1031-4) seek a relation between electromyography (EMG) and anal manometry of the external anal sphincter and compare the effectiveness of the invasive concentric needle technique with that of two non-invasive ones, a sponge electrode and a hard anal plug electrode. The amplitude of the EMG signal measured with the hard anal plug electrode was much less than that measured with the sponge electrode. They assumed that the sponge electrode had better contact in the anal canal than the hard anal plug electrode.

We would like to point out a further factor that may be important in EMG recording from striated muscle by the sponge and hard anal plug electrodes. We note in the article of Sørensen et al that the hard anal plug has electrode plates orientated circularly. It is accepted that bipolar surface electrodes must be placed, for recording from striated muscle, in the direction of the muscle fibres because of the increased longitudinal conductivity of the muscle. ${ }^{\prime}$ Each electrode should be connected to either side of a balanced amplifier with a third electrode connected to earth. ${ }^{2}$ The two electrodes of the anal plug should then be placed, equally separated, on the circumference of the plug with the plates on the long axis.

We have compared two non-invasive plug electrodes: one of these had a circular and the other longitudinal orientation of their metal plates. A much greater EMG signal was recorded from the external anal sphincter both at rest and during voluntary contraction with the longitudinally orientated plates electrode. The anal plug electrode with longitudinal plates has also been compared with invasive wire electrodes and has shown a significant correlation between the rectified integrated EMG voltage obtained from the external sphincter during resting, squeeze, and strain manoeuvres. This emphasises the importance of the orientation of the electrode plates in recording the external anal sphincter EMG.

The orientation of the electrode plates in the sponge electrode illustrated by Sørensen et $a$ seems to be a longitudinal one and is the one which showed good correlation with anal manometry. In contrast, there was no correlation with the EMG voltage obtained by the hard anal plug (circular plates) electrode used by them and anal manometry, as might have been expected from the first principles of EMG recording. Perry et al (1988) have also advocated a hard anal plug electrode with a longitudinally orientated plate. ${ }^{+}$Furthermore, we have shown that it can be used highly effectively in recording the sphincter EMG in anismus and in measuring the latency of the pudendo-anal reflex.

M PAPACHRYSOSTOMOU N R BINNIE A N SMITH University Department of Surgery, Edinburgh Hospital Edinburgh EH4 $2 \mathrm{XU}$
JE, ed, Computer-aided electromyography. Prog Clin Neurophysiol 1983; 10: 1-51.

2 Lenman JAR, Ritchie AE, Simpson JA. Clinical electromyography (3rd ed). London: Pitman Books, 1983: 16

3 Binnie NR, Kawimbe BM, Papachrysostomou M, Clare N, Smith AN. The importance of the orientation of the electrode plates in recording the external anal sphincter EMG by non-invasive anal plug electrodes. Int $\mathcal{F}$ Colorect Dis 1991; 6 : 5-8.

4 Perry JD, Hullett LT, Bollinger JR. EMG biofeedback treatment of incontinence, and other disorders of the pelvic musculature. Proceedings of the Biofeedback Society of America. Colorado, the Biofeedback Society
USA, 26 March, 1988.

\section{Reply}

SIR, - We have used the hard anal plug electrode for a number of years in investigating patients with defecation disorders. However, in patients with faecal incontinence the electromyographic (EMG) recordings with this electrode were of poor quality, which is why we started to use the sponge electrode as well. Our results show, that the sponge electrode is the better of the two electrodes in discriminating between incontinent and continent patients and we suggest that this is due to a better signal/ noise relation, probably because of better electrode contact.

Binnie et al (Int $\mathcal{F}$ Colorect Dis 1991; 6: 5-8) have shown that the orientation of the electrodes is important in recording anal EMG. However, the sponge electrode we used has two circular pick-up plates with a diameter of approximately $5 \mathrm{~mm}$ which is why it is impossible to conclude anything about the significance of the orientation of the electrode. We carefully place the electrode in the anal canal with the pick-up plates situated at 3 and 9 o'clock where the external sphincter is widest. Binnie et al apparently placed their electrodes at between 6 and 12 o'clock. This position will include EMG signals from the puborectal muscle as well, which explains the good results obtained in patients with anismus.

We conclude that the hard anal plug electrode should not be used: the results of Binnie et al confirm this.

J CHRISTIANSEN Department of Surgery D, Glostrup Hospital, University of Copenhagen

Septicaemia after colonoscopy in patients with cirrhosis

SIR, - Thornton and Losowsky highlight an important problem in their article 'Septicaemia after colonoscopy in patients with cirrhosis' (Gut 1991; 32: 450-1). However, the role of endotoxins in this condition was not mentioned. Endotoxins are important bacterial factors for the development of the clinical syndrome of Gram negative septicaemia, ' and have been shown to produce independently biological effects of this condition. ${ }^{2}$ Endotoxins have been detected in venous blood of $>50 \%$ of patients after colonoscopy, but produce no clinical effects in the presence of normal liver function. ${ }^{3}$ However, portal systemic shunting in the cirrhotic patient may allow much higher levels of endotoxin to reach the systemic circulation, leading to the clinical symptoms associated with septicaemia. Antibiotic therapy may further liberate endotoxins bound to the bacterial cell membrane, ${ }^{+}$leading to deterioration in the clinical condition of a susceptible patient. Therefore, should cirrhotic patients undergoing colonoscopy receive prophylaxis not against bacteria with antibiotics but against endotoxaemia using Centoxin (human monoclonal $\operatorname{IgM}$ antibody targeted against endotoxin)?

MARK WELCH DAVID DURRANS

Department of Vascular Surgery, Manchester Roval Infirmary, Oxford Road

Manchester M13 9WI

1 van Deventer SJH, Buler HR, ten Cate JW, Sturk A, Pauw W. Endotoxaemia: an early predictor of A, Pauw W. Endotoxaemia: an early predictor of
septicaemia in febrile patients. Lancet $1988 ; \mathrm{i}$ : septicaemi.

2 Morrison DC, Ulevitch RJ. The effects of bacterial endotoxins on host mediation systems. Am 7 Path 1978; 93: 527-618.

3 Kelley CJ, Ingoldby CJH, Blenkharn JI, Wood CB. Colonoscopy related endotoxemia. Surg Gynecol Obstet 1985; 161: 332-4.

4 Shenep JL, Flynn PM, Barrett FF, Stidham GL, Westenkirchner DF. Serial quantitation of endotoxemia and bacteremia during therapy for toxemia and bacteremia during therapy for
Gram-negative bacterial sepsis. F Infect Dis 1988; 157: 565-8.

Reply

SIR, - We thank Mr Welch and Mr Durrans for their interest in our paper. We did consider discussing endotoxaemia after colonoscopy but did not do so as we felt it had not been shown to be of definite clinical importance. Thus, while there is evidence that systemic endotoxaemia is more frequent after colonoscopy in patients with liver disease, this has not been found to be associated with any detectable clinical consequences in the absence of bacteraemia. ${ }^{1}$

$\mathrm{Mr}$ Welch and $\mathrm{Mr}$ Durrans suggest that in patients with cirrhosis undergoing colonoscopy, prophylaxis with anti-endotoxin therapy (Centoxin) may be preferable to antibiotics. We feel that if prophylaxis is to be given, antibiotics are more likely to be effective in preventing serious sequelae and, as Centoxin costs $£ 2200$ each dose, antibiotics are much the cheaper option.

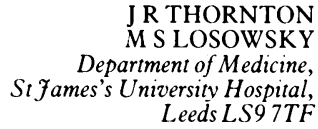

1 Jacob AI, Goldberg PK, Bloom N, Degenshein GA, Kozinn PJ. Endotoxin and bacteria in portal blood. Gastroenterology 1977; 72: 1268-70.

2 Kiss A, Ferenci P, Graninger W, Pamperl H, Pot $z i$ $\mathrm{R}$, Meryn S. Endotoxaemia following colonoscopy. Endoscopy 1983; 15: 2+6.

An atlas of rectal endosonography. By J Beynon, G Feifel, U Hildebrandt, and $\mathrm{N} \mathrm{H}$ McC Mortensen. (Pp 111; illustrated; DM 175.) London: Springer Verlag, 1991

Rectal endosonography is proving to be a very useful method for assessing malignant as well as non-malignant disorders. This book provides a simple and useful guide to ultrasonographic imaging of the anorectum. The technique of rectal endosonography is well described. The images are clear and examples 